American Journal of Environmental Sciences 6 (2): 177-183, 2010

ISSN 1553-345X

(C) 2010 Science Publications

\title{
Sensitivity of Fish Landings to Some Meteorological Parameters: A Case Study
}

\author{
${ }^{1}$ Madihah Jafar-Sidik, ${ }^{1}$ Than Aung and ${ }^{2}$ Awnesh Singh \\ ${ }^{1}$ Borneo Research Institute, University of Malaysia Sabah, 88999 Kota Kinabalu, Sabah, Malaysia \\ ${ }^{2}$ Research Institute for Development, Laboratory Studies in Geophysics and Oceanography Space, \\ 14 Avenue Edouard Belin, 31400 Toulouse, France
}

\begin{abstract}
Problem statement: A widely held belief that climate change has impacts on sustainable fish catch leads us to find out how these effects influence fish landings in Sabah, Malaysia, especially for the west and east coasts, based upon monsoonal periods. Correlation of fish landings with rainfall suggests that local fish landing is believed to be sensitive to the effects of climate change. Approach: Rainfall, temperature, wind, the Southern Oscillation Index (SOI) and fish landings time series for 3 specific regions (Kota Kinabalu (KK), Tawau and Sandakan) have been studied using available local data for the last 9 years. Results: Results indicated significant fish landing variations due to the fluctuation of these meteorological parameters, for example, $\sim 20 \%$ reduction is found during Northeast (NE) monsoon at KK. Heavy rainfall correlates well with high fish landings when fish landings lead rainfall by 1 month. Fish landings and temperature were also highly correlated. Fish landings leads wind stress by 1-2 months with $99 \%$ certainty and it is high when the wind direction is between $150-200^{\circ}$ from north (approximately for South Easterlies and South Westerlies). Conclusion: The results confirmed that fish landing is low during NE monsoon period. In regard to the effect of El Nino Southern Oscillation (ENSO), low or negative SOI indicates high fish landings.
\end{abstract}

Key words: Rainfall, temperature, wind, climate, monsoon

\section{INTRODUCTION}

When investigating climatic effects on fish landings, the focus has been made on commercially important and popular dinner-table fish species, such as, different types of grouper (Bleeker's, Marble, Green, Greasy, Mottled), wrasse (Maori, Green), sea bass (Humpback, Blue-spotted, Squaretail), snapper (Mangrove red, White blotched), giant sea-perch, glasseyed perch, white sea bream, spotted sweetlips, footballer trout, vermicular leopard cod and few other species in this study, especially for the Kota Kinabalu (KK) area in the west and, for comparison purpose, Sandakan and Tawau in the east of Sabah, Malaysia. More detailed list of fish species in Sabah can be found in Institute Penyelidikan Marin Borneo (2003) and earlier ones in Herre (1933). There have been a number of studies demonstrating the sensibility of pelagic species to El Nino Southern Oscillation (ENSO) conditions in different other areas (Aaheim and Sygna, 2000; Beamish and Bouillon, 1993; Chen et al., 1994; Eide and Heen, 2002; Lea, 2000; Roessig et al., 2004; Ruello, 1973). It is reasonable to expect that on-going climate change may affect fish catch and landings one way or another. The difficulty involved in explaining the effect of climate parameters on fish catch and landings arises from the lack of reliable meteorological data together with the long term fish landings data.

The main objectives of this study are to establish whether there is any link between rainfall, temperature, wind, SOI and the fish landings in some strategic areas in Sabah during the monsoonal and non-monsoonal seasons. The increasing numbers of typhoons (also called tropical cyclones) in the West Pacific Ocean have contributed to severe weather while climate change is expected to worsen the existing conditions and create new vulnerabilities to the fisheries industry (Roessig et al., 2004). This study will identify some known and unknown factors that can influence fish landings in Sabah. The results of this study are important for the local fisheries industry for appropriate preparation in the future. Also, understanding the need for studies on climate influences and fisheries is important to ensure ecologically sound, economically sustainable and socially equitable development in Sabah.

Corresponding Author: Awnesh Singh, Research Institute for Development, Laboratory Studies in Geophysics and Oceanography Space, 14 Avenue Edouard Belin, 31400 Toulouse, France Tel: +33 (0) 561332719 


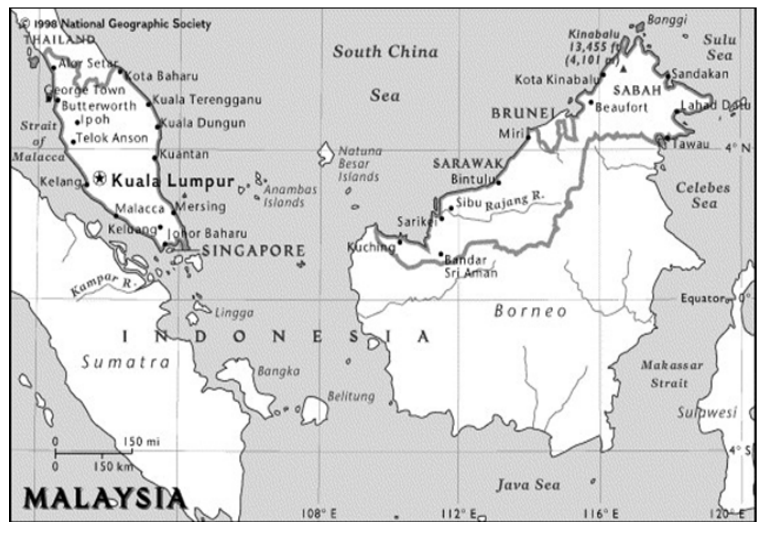

Fig. 1: Map of Malaysia showing Sabah at the northern edge of Borneo

Background of study area: Sabah is the second largest Malaysian state situated on the northern tip of the island of Borneo (Fig. 1) covering an area of $73711 \mathrm{~km}^{2}$ with a coastline of $1600 \mathrm{~km}$ facing the sea (considering all coasts with direct marine exposure (lagoons, mainland and islands) the total length of the Sabah coastline becomes around $4315 \mathrm{~km}$ ). It also shares a border with the province of East Kalimantan of Indonesia in the south. In spite of its status as a Malaysian state, Sabah remains a disputed territory; The Philippines have a dormant claim over much of the eastern part of the territory (Cooke, 2003). The capital of Sabah is Kota Kinabalu, formerly known as Jesselton, where our study is mainly focused on.

Sabah is known as 'Sabah, Negeri Di Bawah Bayu', which means 'Sabah, the land below the wind', because of its location. It is situated below the typhoon and monsoon belt (just south of the typhoon-prone region around the Philippines) and has a uniquely diverse population of approximately $2.6 \mathrm{~m}$ consisting of 32 ethnic communities. It is basically an agricultural state. Over $70 \%$ of the population live in rural areas and the majority are dependent directly or indirectly on agriculture, livestock and fisheries for their livelihood and these industries contribute very significantly towards the export earnings of the state. Sabah is a key exporter of marine fish products in Malaysia (Cooke, 2003).

Brief description on monsoon: The word monsoon is derived from the Arabic word mausim meaning season. Ancient traders plying in the Indian Ocean and adjoining Arabian Sea used it to describe a system of alternating winds which blows persistently from the northeast during the northern hemisphere winter and from the opposite direction, the southwest, during the northern hemisphere summer. The most famous monsoon is the Indian monsoon. The intense rainfall in these regions can cause massive flooding and destruction of crops. In dry climates, monsoons are an important replenishment for life as water is brought back into the drought-stricken zones of the world (Cooke, 2003).

The weather in Malaysia is characterized by two monsoon regimes, namely, the South West (SW) monsoon from late May to September and the Northeast (NE) monsoon from November to March. It is to be noted that these months are not rigid to identify the monsoonal periods due to unexpected changes of the wind system. The months between the monsoons are known as the Inter-Season (IS) period. The northeast monsoon brings heavy rainfall, particularly to the east coast states of Peninsular Malaysia and western Sarawak, whereas the southwest monsoon normally signifies relatively dry weather. The primary cause of monsoon comes from global winds and air pressure, though the exact cause is still not completely understood.

General weather conditions in Sabah: The average atmospheric temperature is between $23-32^{\circ} \mathrm{C}$ and rainfall is approximately $2400 \mathrm{~mm}$ per annum, although it is not uniformly distributed throughout the year. The monsoonal season plays an important role in all activities of Sabah (Institute Penyelidikan Marin Borneo, 2003).

The dry season is normally in the months of February to April/May while the wet season occurs during the monsoon seasons. The northeast monsoon, usually from October to January (or February), brings the heaviest rains of the year to the eastern coast of Sabah. The southwest monsoon, usually from May to August (or September), brings heavy rains to the western coast of Sabah (Cooke, 2003).

Status of fisheries in Sabah: According to Cabanban and Biusing (1999) and Biusing et al. (1995), Sabah produces approximately $15 \%$ of Malaysia's fish catch and our study areas alone contribute approximately $70 \%$ of Sabah's marine fisheries landings annually. Fisheries production in Sabah can be classified as marine fisheries and aquaculture. The majority of Sabah's fishers are small-scale fishermen maintaining a subsistence lifestyle. However, the majority of Sabah's fish landings come from large-and medium-scale trawlers and purse-seines. Small pelagic fish, such as, mackerel, prawn, squid and other fin-fish comprise the bulk of commercial fish landings. The marine fishing industry in Sabah has produced fish not only enough for self consumption but also surplus for export. An astonishing 200-300 species of fish and invertebrates 
are landed regularly in Sabah's markets. To date, there are more than 600 species of edible marine fishes found in Sabah's fish markets (Institute Penyelidikan Marin Borneo, 2003). The major foreign markets for fish and fish products of Sabah are found in Brunei, Philippines, Japan, Singapore, Hong Kong and Taiwan while the secondary markets are in Europe, Australia and the United States of America. A substantial volume is also sold to Peninsular Malaysia.

There is increasing evidence that inshore fisheries throughout Sabah, as in many other areas, are in decline. Around Sabah, fishing pressure is intense and there has been considerable diversification of fisheries effort. All of the known resources are exploited. Sabah's reef fish landings have decreased since its peak in the 1980s (Cabanban and Biusing, 1999). Destructive fishing methods have also damaged reef habitat throughout Sabah (Biusing et al., 1995), contributing to the decline of reef resources. Habitat destruction and pollution, due to logging activities and extensive agricultural development in Sabah in recent years, have somehow greatly affected the inland fisheries of Sabah. Sabah is the largest oil palm producer in Malaysia. Unfortunately, it has caused negative impact on freshwater fish habitat in the states, especially in the east coast region where most of the oil palm plantations is found (Cooke, 2003). Thus, the fish population and the landing of freshwater fish in the state have been dwindling rapidly over the years.

\section{MATERIALS AND METHODS}

Fish landing raw data (in tonnes per month) of various fish at the daily markets of the study areas were provided by the department of fisheries, Sabah for the study period. This dataset is based on daily logbook records with an estimated error of $\sim 10 \%$ due to the nature of recording and fluctuations by market requirements. Meteorological data, including rainfall $(\mathrm{mm})$, average temperature $\left({ }^{\circ} \mathrm{C}\right)$, average wind speed $\left(\mathrm{m} \mathrm{sec}{ }^{-1}\right.$ ) and dominant wind direction (degree from North), were provided by the Malaysian Meteorology Service, Sabah. For Kota Kinabalu in the west and Tawau in the east, regular data were available from 2000-2008. Due to missing and irregular data for the Sandakan area (east coast of Sabah), only data between 2003 and 2007 were analyses in this study as a backup for the east coast to enhance the findings from Tawau. Monthly SOI values for the study period were obtained from the Bureau of Metrology, Melbourne, Australia. All analyses data were grouped and regrouped appropriately for monsoonal and non-monsoonal seasons for further analysis.

\section{RESULTS AND DISCUSSION}

Effects of monsoonal seasons on fish landings: Fish landings data for the three different areas were separated for the SW monsoon, NE monsoon and IS inter-monsoon season and monthly averages were calculated. The results are shown in Fig. 2. A noticeable point is that fish landings in $\mathrm{KK}$ area is almost the twice that of the other areas in the east coast. It does not mean, however, that the Sulu Sea and Celebus Sea are less productive in fisheries. Instead, KK has a higher fishermen population and more fishing facilities.

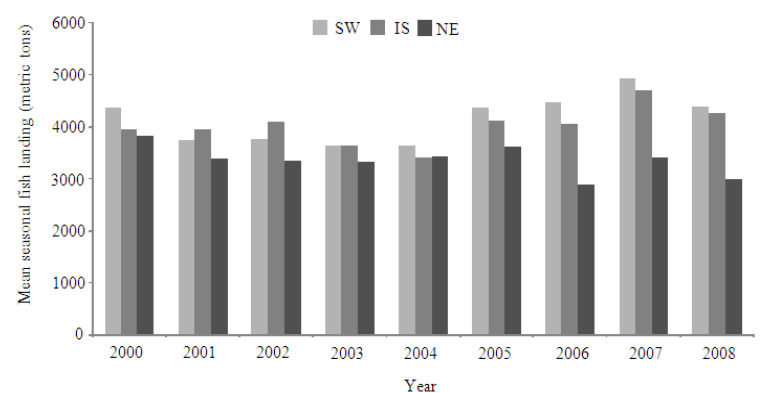

(a)

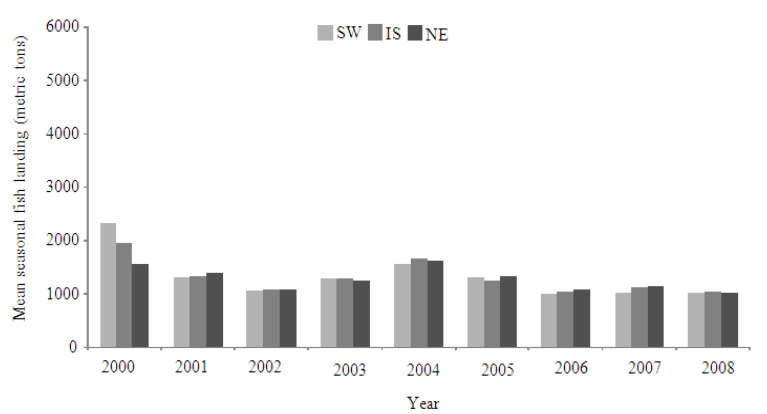

(b)

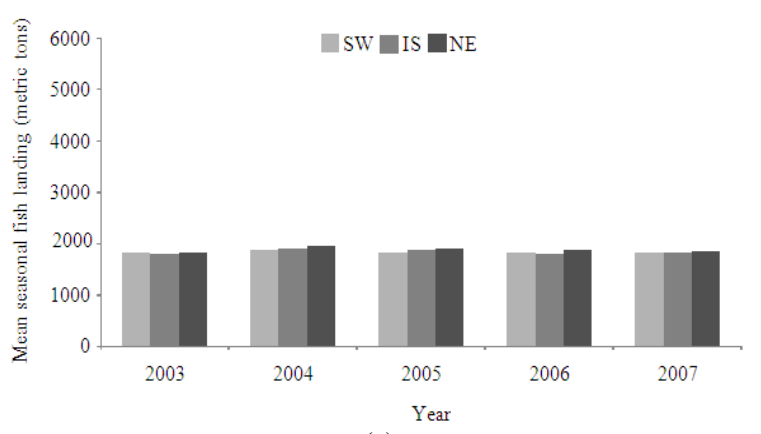

(c)

Fig. 2: Fish landings (in metric tons) during monsoonal seasons in (a) Kota Kinabalu, (b) Tawau and (c) Sandakan 
It is to be noted that our focus is only on fish landings at the markets and not the abundance of fish in the areas or fish catch. It is clearly seen in Fig. 2a that fish landings in $\mathrm{KK}$ area is the lowest during NE monsoon while the other two periods are more favorable for fish landings. In Tawau and Sandakan on the eastern side of Sabah, fish landings are almost the same for all seasons and the seasonal effect is not clearly noticeable.

In order to enhance our argument, Fig. 3 illustrates the overall seasonal fish landings in KK for the entire 9 year study period. As stated earlier, fish landings in $\mathrm{KK}$ area is found to be the lowest during NE monsoon and the other two periods have almost the same amount of fish landings. When an analysis is done on a monthly basis, it is found that higher fish landings take place from March to October. It simply means that November to February (NE monsoon) is not favorable for fish landings and is $\sim 20 \%$ less than other periods in KK.

Influence of rainfall on fish landings: According to our usual understanding, monsoon carries rain to Sabah and it is generally known as the wet season. However, rainfall in $\mathrm{KK}$ area during NE monsoon is relatively lower than other times. As shown in Fig. 1, KK is situated on the western side of Sabah facing the South China Sea and the mountainous main land of Sabah is blocking the NE monsoon wind. The commonly known rain shadow effect is evident in $\mathrm{KK}$ side and rainfall is abundant on the eastern side of Sabah, such as, in Sandakan and Tawau during the NE monsoon. Figure 4 shows the time series of fish landings and rainfall at the three different areas.

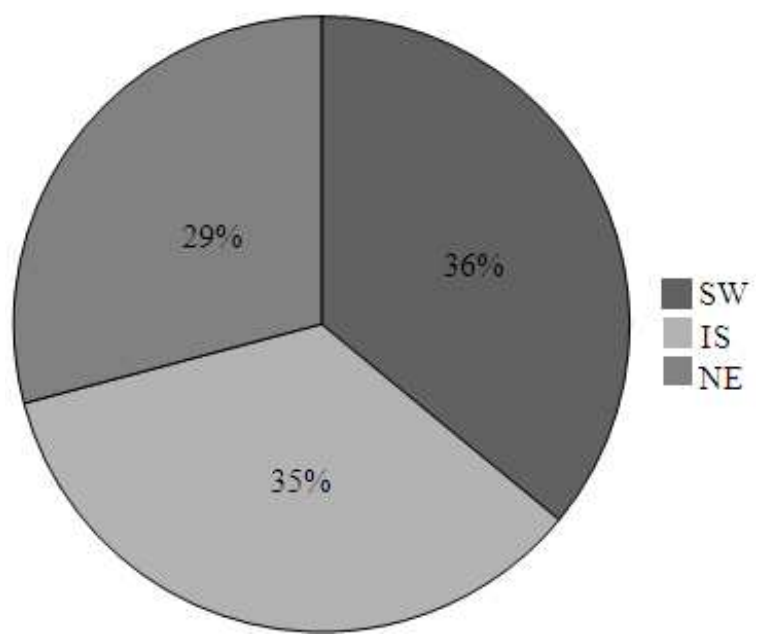

Fig. 3: Mean Fish landings during monsoonal seasons at KK for the study period (2000-2008)
It can be seen (Fig. 4a) that heavy rainfall brings high fish landings in $\mathrm{KK}$ area with a slight time lag. Monthly rainfall in $\mathrm{KK}$ is varying between 0 and $600 \mathrm{~mm}$ per month. Figure $4 \mathrm{~b}$ shows monthly rainfall in Tawau and fish landings response to rain is similar to the situation in $\mathrm{KK}$, although total fish landing is not as much as in KK. Fluctuation in rainfall is not as high as in KK and average monthly rainfall is $\sim 200 \pm 30 \mathrm{~mm}$. Rainfall in the Sandakan area is around $200 \mathrm{~mm}$ (Fig. 4c), however, the value goes up to $1000 \mathrm{~mm}$ during the NE monsoon. Fish landing in Sandakan is around 2000 tones per month and does not clearly respond to the change in rainfall.

Temperature and fish landings: Fish landings and temperature time series are shown in Fig. 5. Monthly average temperature at KK fluctuates between $26-28.5^{\circ} \mathrm{C}$ with no sharp temperature change.

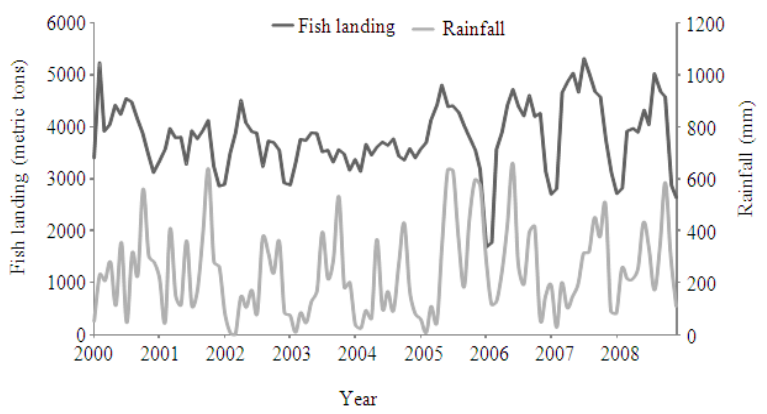

(a)

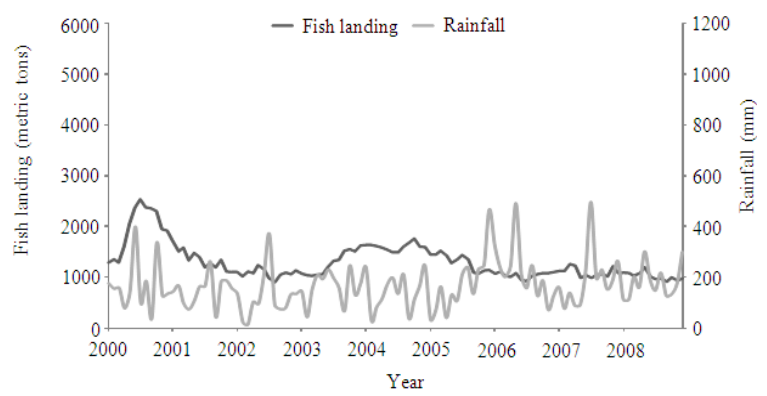

(b)

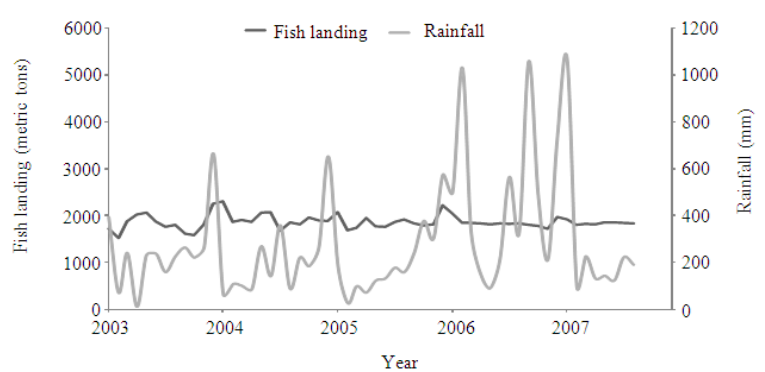

(c)

Fig. 4: Monthly rainfall and Fish landings in (a) Kota Kinabalu, (b) Tawau and (c) Sandakan 


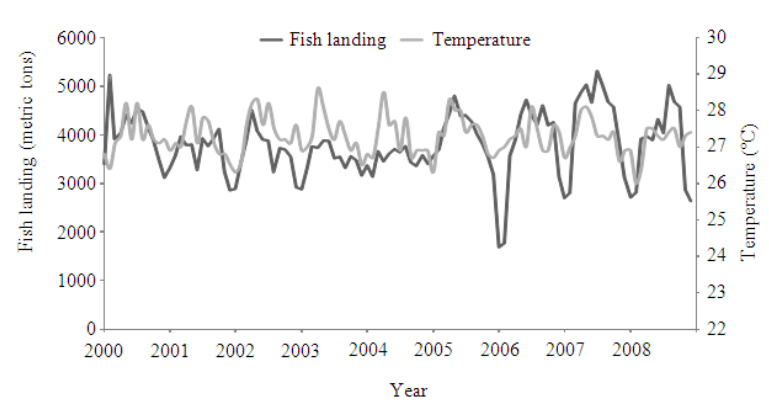

(a)
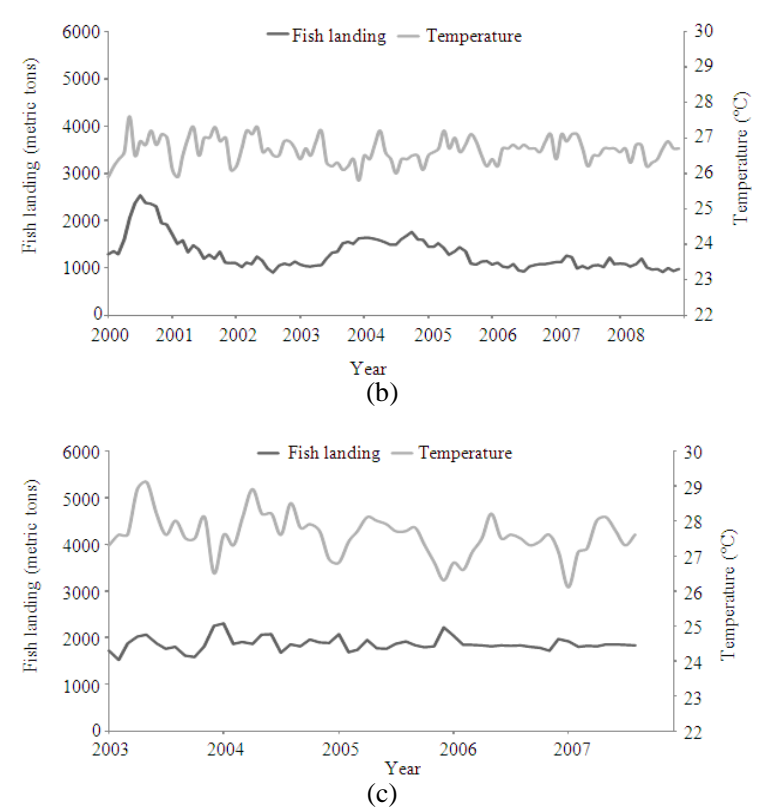

Fig. 5: Fish landings and temperature in (a) Kota Kinabalu, (b) Tawau and (c) Sandakan

However, it is seen consistently that fish landings drop just before the temperature falls (Fig. 5a). Monthly average temperature at Tawau is less fluctuating than $\mathrm{KK}$ and the temperature is mostly $27^{\circ} \mathrm{C}$ (Fig. 5b). As mentioned earlier, fish landings in Tawau are lower than for KK. It indicates that the effect of temperature changes is minimal on fish landings in Tawau area.

Fish landings at Sandakan do not change much and the monthly average is approximately 2000 tonnes. However, temperature fluctuates between $26-29^{\circ} \mathrm{C}$ and it can be seen like in $\mathrm{KK}$ (on a lesser scale) that fish landings drop just before the temperature falls (Fig. 5c).

Fish landings against wind: The relation between fish landings and wind speed in KK is shown in Fig. 6a and b. It can be seen that high wind is bringing high fish landings in KK. At the same time, when we look at the wind direction (Fig. 6b), fish landing is high when the wind direction is between $150-200^{\circ}$ from north, which is roughly the South Easterlies and South Westerlies.

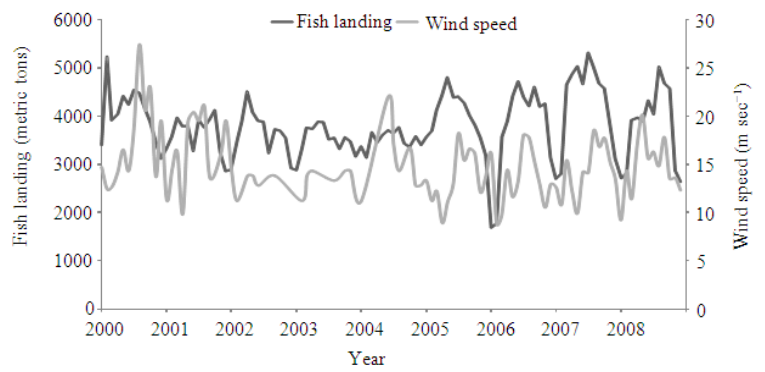

(a)

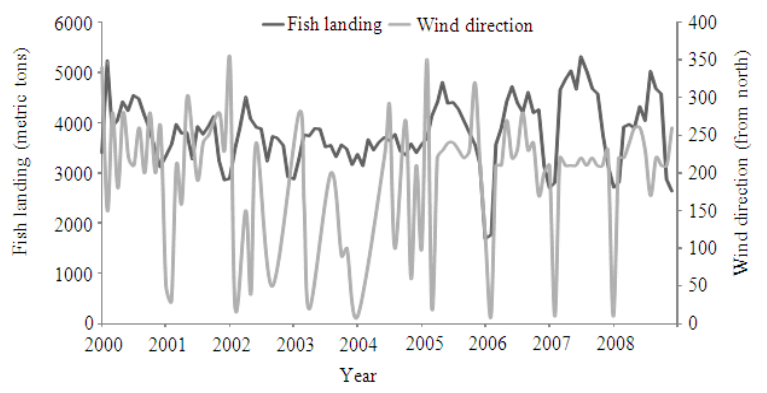

(b)

Fig. 6: Fish landings and Wind (a) Wind Speed and (b) Wind Direction at KK

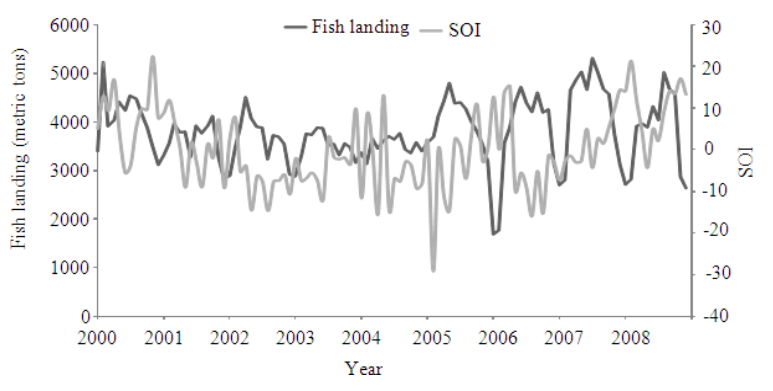

Fig. 7: Fish landings at KK and SOI

It somewhat confirms that fish landing is low during the NE monsoon period. Due to lesser fluctuation of fish landings in other two areas, the effect of wind is not clearly evident as it is in $\mathrm{KK}$ and not shown.

Fish landings versus SOI: Having analyzed the effects of several meteorological parameters on fish landings at the east and west coasts of Sabah, we look at the general influence of SOI on fish landings in KK (Fig. 7), since ENSO event is regarded as a global phenomena. In this analysis, focus is made on KK only due to the fact that other areas on the east coast of Sabah have almost the same fish landings throughout the study period. It is clearly evident that negative SOI is favoring the higher fish landings in $\mathrm{KK}$ area. With a slight time lag, positive SOI indicates the lower fish landings for the period between 2000 and 2008 in the west coast of Sabah. 


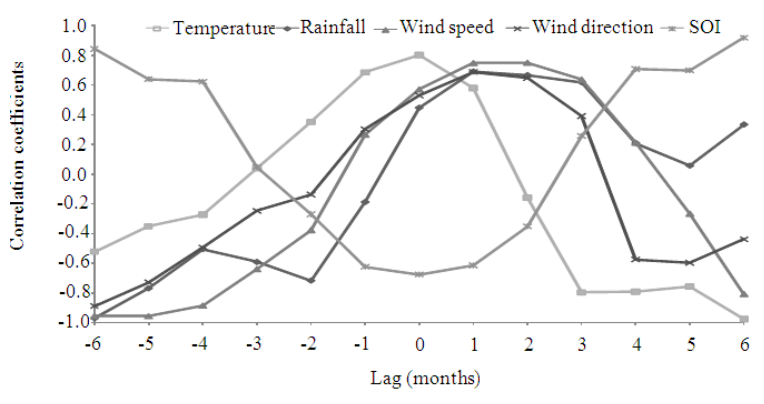

Fig. 8: Correlation Coefficients between time series of monthly Fish Landing and Different Variables (-ve lag means variable leads)

Brief statistical analysis: Correlation coefficients between time series of monthly fish landing (average of all similar months) and different meteorological variables for the KK area are shown in Fig. 8. Here negative lag means the variable leads the fish landings. The data considered are for the 9-years period. The correlation coefficient between rainfall and fish landings is +0.69 with fish landings leading by 1 month. When temperature is considered, the correlation coefficient is +0.8 at zero lag, meaning fish landings and temperature are directly correlated. It is interesting to note that wind has considerable effect on fish landings. The correlation coefficient for wind speed and fish landings is found to be +0.75 with fish landings leading by $1-2$ months. Similarly fish landings lead dominant wind direction by 1 month. The impact of ENSO phenomena and SOI are quite pronounced on fish landings in KK area of Sabah although the locality is not in the Pacific Ocean. In addition, the effect of SOI on local fish landings has not been looked at before. The correlation coefficient of fish landings and SOI is -0.68 and low or negative SOI is indicating high fish landings with no time lag. All correlations are significant at the $95 \%$ confidence level.

\section{CONCLUSION}

Fish in Malaysia is a common food. The per capita consumption of fish and other seafood in the country is estimated to be around $30-35 \mathrm{~kg}$. This represents more than two-thirds of the total animal protein consumed per capita locally. By the year 2010, when the population in Malaysia is projected to be around $29 \mathrm{~m}$, the total demand for fish would have increased to more than $1 \mathrm{~m}$ tonnes (Cooke, 2003).

Our case study has identified a clear link between fish landings and climate variables in Sabah. Fishermen will be going out to the sea on a regular basis, but the catch will vary based upon some meteorological factors. Heavy rainfall indicates higher fish landings with the later leading by 1 month. Temperature also has the same effect; Meaning fish landings and temperature are directly correlated. In addition, fish landings lead wind speed by 1-2 months. Fish landing is also high when the wind direction is between $150-200^{\circ} \mathrm{C}$ from north; these directions roughly represent the South Easterlies and South Westerlies. It indirectly confirms why the fish landing is $\sim 20 \%$ low during NE monsoon period in KK area. The globally popular ENSO phenomenon has effect on fish landings in KK with low or negative SOI indicating high fish landings at zero lag. Fisheries should not be managed without including proactive responses to changes in rainfall, temperature, wind and the SOI and their predicted trends.

The fishing and aquaculture industry in Sabah has great potential for development. Among the key reasons are the yet untapped fisheries resources, established technology and the strong government support. Even though this sector faces a number of constraints and problems, these by no means will hamper the development of the industry. How this industry will develop in the next few years will depend on the close cooperation between the private sector and the government. The benefit is clear: The State of Sabah will become the premier fish-producing state in Malaysia.

\section{REFERENCES}

Aaheim, A. and L. Sygna, 2000. Economic Impacts of Climate Change on Tuna Fisheries in Fiji Islands and Kiribati. CICERO Report 4, Centre for International Climate and Environmental Research, Oslo, Norway, pp: 21.

Beamish, R.J. and D.R. Bouillon, 1993. Pacific salmon production trends in relation to climate. Can. J. Fish. Aquat. Sci., 50: 1002-1016.

Biusing, E.R., A.C. Cambang and R. Jumin, 1995. Demersal Fish Resources Survey in the West Coast of Sabah. Apr. 23- July 26, Fisheries Department Malaysia, Malaysia, pp: 35.

Cabanban, A.S. and R.E. Biusing, 1999. Coral reef fisheries and their contribution to marine fish production in Sabah, Malaysia. Proceeding of the Workshop on Aquaculture of Coral Reef Fishes and Sustainable Reef Fisheries, Dec. 4-8, Institute of Development Studies, Kota Kinabalu, Malaysia.

Chen, Y.L., H.Y. Chen and W.N. Tzeng, 1994. Reappraisal of the importance of rainfall in affecting catches of Anguilla japonica elvers in Taiwan. Aust. J. Mar. Freshwater Res., 45: 185-190. http://www.publish.csiro.au/paper/MF9940185.htm 
Cooke, F.M., 2003. Living at the Top End: Communities and Natural Resource Use in the Kudat/Banggi Region of Northern Sabah. WWF, Malaysia, pp: 45.

Eide, A. and K. Heen, 2002. Economic impacts of global warming: A study to the fishing industry in North Norway. Fish. Res., 56: 261-274. DOI: 10.1016/S0165-7836(01)00324-1

Herre, A.W., 1933. A checklist of fishes from Sandakan, British North Borneo. J. Pan-Pacif. Res. Inst., 8: 2-5.

Institute Penyelidikan Marin Borneo, (IPMB), 2003. Research Report on Knowledge and views on the Establishment Masyarakt Banggi Island Taman Tun. Unpublished Report, Kota Kinabalu, Malaysia, pp: 36.
Lea, R., 2000. Observations on fishes associated with the 1997-1998 El Nino off California. CalCOFI Report, 41: 117-129.

Roessig, J., C. Woodley, J. Cech and L. Hansen, 2004. Effects of global climate change on marine and estuarine fishes and fisheries. Rev. Fish Biol. Fish., 14: 251-275. DOI: 10.1007/s11160-004-6749-0

Ruello, N., 1973. The influence of rainfall on the distribution and abundance of the school prawn in the Hunter River region (Australia). Mar. Biol., 23: 221-228. DOI: 10.1007/BF00389488 